\title{
A K-complementarity Technique for Forming Groups of Tutors in Intelligent Learning Environments
}

\author{
Yacine Lafifi, Safia Bendjebar and Amina Zedadra \\ LabSTIC Laboratory, University 8 May 1945 Guelma, Algeria
}

In e-learning environments, tutors perform the main function of tutoring. They follow up learners and answer their assistance requests which require different skills. These requests may not belong to the tutors' skills and competencies, so collaboration among other tutors is expected. In fact, this collaboration can improve tutors' skills and provide learners with effective monitoring. It can be permanent and adaptive, according to learners' needs and requests. Grouping tutors with different skills is the aim of this research. In this paper, a new technique for grouping tutors is presented. The proposed technique is called K-complementarity. It is based on the complementarity of roles that are assigned to tutors. $\mathrm{K}$-complementarity is based on tutor model and aims at obtaining $\mathrm{K}$ groups of tutors who have the most of the roles and skills. The proposed technique has been used by a Computer-Supported Collaborative Tutoring (CSCTT) system. This system had been tested in an Algerian University. The obtained results showed that the groups' members are heterogeneous and the groups are homogeneous. Furthermore, each group had more than $80 \%$ of the roles by combining those of its members. So, these results can be considered as acceptable and very encouraging.

Keywords: forming groups, collaborative tutoring, Kcomplementarity, tutor model, complementarity coefficient, intelligent learning environments

\section{Introduction and Motivation}

Tutoring is a human activity, which has been applied in several fields. In the educational field, this task has become indispensable, especially in higher education institutions. The primary objective of tutoring is to support the learners throughout the learning so that it fully reaches the educational objectives set by the educational institution (Peraya, 2011). Furthermore, it aims at supporting all the activities of learners and assisting them to find learning difficulties and problems. In other words, distance tutoring or e-tutoring is referred to all the activities that support learners in their learning process (Kopp et al., 2012).

With the development of information and communication technologies, many environments have been implemented to support the educational activities of learners (learning, assessment, collaboration, etc.). Tutoring task was supported by these systems explicitly or implicitly. Indeed, in the majority of these systems, support to learners is provided. This support can take many forms: content and path personalization, adaptive interfaces, virtual or real scheduling meetings, etc. Support process is carried out by a human actor or by an artificial entity (as in the case of Intelligent Tutoring Systems). In Intelligent Learning Environments (ILE), this actor is called: e-tutor (Shaoming, 2011; Kopp et al., 2012). The roles of e-tutors in distance learning are numerous (Decamps \& Depover, 2011). Furthermore, this actor has several names: mentor, coach, facilitator, etc.

In the literature, there are many researches that are interesting in learners' monitoring process, which is ensured by tutors (Dolmans et al., 1999; Jelfs et al., 2009; Kopp et al., 2012; Aarnio et al., 2013; Hayashi et al., 2013). We found that there are many difficulties and problems met by both learners and tutors. In fact, learning systems adopting tutoring task in its various forms have some shortcomings. First of all, learners' needs don't belong within the range of tutors' skills (Lafifi et al., 2010). 
Secondly, although tutors' roles are multiple, several tutors had difficulties to understand all these roles. Thirdly, the absence of tutors for personal or technical reasons is another problem. Indeed, if learners recognize tutors' intellectual and moral qualities, they often regret their lack of availability (Decamps \& Depover, 2011). Followed without the presence of the tutor, some learners have the feeling of being "lost" and "forgotten" on the learning platform and the motivation found quickly affected. Finally, tutors who practice this job for the first time say that it is difficult to understand their roles (Glikman, 2011). So, training task of novice tutors is expected.

Several research questions motivate our contributions. The first one is: how to represent tutors' roles? The aim is facilitating the affectation of tutors to learners and facilitating tutor searching task. The second question is how to improve tutors' skills? The goal is to contribute to the formation of novice tutors on one hand and to benefit from the experiences of other tutors on the other. The last question is how can we measure the improvement of tutors' skills and what is the effect of this improvement on learners' monitoring?

In order to answer these research questions, first, we propose to identify the required tutors' roles. Then, we propose to benefit from the positive effects of collaboration among tutors to meet the requirements of all learners who need help and to improve the performance of tutors, especially the novice ones. In other words, we want to bring together tutors with complementary roles to ensure that each group of tutors has the most of the roles. These tutors work together using communication tools to monitor and guide their learners.

The aim of this research is to propose a new technique that aims at grouping tutors according to their skills and complementary roles. To facilitate this task, each tutor must be represented by a model that has all his features and skills. So, our contributions are particularly related to the proposal of a new structure of the tutor model and the presentation of a new clustering technique of tutors based on complementarity principle.

The rest of the paper is organized as follows. In Section 2, we give some research works dealing with tutors' roles and grouping of users. Section 3 is devoted to the presentation of our new grouping technique, which is the K-complementarity. To validate our approach, a learning system adopting the new clustering technique has been implemented. Section 4 is devoted to present the main objectives of this system. The results of an experiment, which was conducted in a higher-education institution, are presented in Section 5. Finally, a conclusion and future works will be presented.

\section{Literature Review}

\subsection{Tutors' Roles and Tasks}

According to Glikman (1999), in distance learning, a few learners seek help on their own initiative. To explain this observation, Glikman evokes different explanations. First, learners can organize themselves to find the information (they need). Then, sometimes they dare not seek help due to the constraint of having to disclose their lack of understanding. Finally, some students do not seek more help because the first contact does not give them satisfaction (Depover \& Quintin, 2011). This help can be provided by human actors called tutors. Nowadays, tutoring is becoming an indispensable task for offering help and assistance.

Due to its many advantages, the tutoring task is adopted in many fields: medicine (Shah et al., 2002; Rhodes \& Jinks, 2005; Kerridge, 2008; Aarnio et al., 2013, Hayashi et al., 2013), education (Barker, 2002; De Smet et al., 2010; Dillenbourg, 2011; Mangenot, 2011; PorayskaPomsta \& Mellish, 2013), higher education (Weigle \& Nelson, 2004; Owen et al., 2006; Xenos \& Papadopoulos, 2007; Jelfs et al., 2009), professional training (Li et al., 2012), chemical engineering (Nisbet et al., 2014), management (Cohen-Scali, 2013), library (Waite et al., 2011), etc.

Some researchers argue that in adults' training, the tutor is responsible by his intervention to facilitate the learning process and monitor their activities. His role is that of an accompanying person, coach or resource-person. He should facilitate knowledge transfer and assist the student in his learning personal process and assimilation of knowledge (Glikman, 2002). The four 
features which appear are: facilitator, coach, guide, and resource-person. On the other hand, "the primary role of the tutor is to discuss with the learners so that the knowledge they build is used in diverse and varied situations" (Salmon, 2003).

Tutors' roles and functions are mostly specific to each distance learning platform (Rodet, 2008). In most distance courses, the tutor has mainly a psychological and methodological role. Other roles are cited by many researchers: guide, evaluator, moderator, etc. According to (Depover \& Quintin, 2011), the function of the online tutor is complex and requires specialized skills in several areas. Indeed, according to Salmon (2000), tutors' skills fall into three main areas: skills related to the management of online exchanges, skills related to the content covered by the course and methodological skills. Other researchers have added administrative aspect or assessment of learning (Bernatchez, 2003; Daele \& Docq, 2002).

As a conclusion about the tutors' roles, we can say that there is confusion about these roles from one researcher to another. This confusion is due to the lack of works about the standardization and the instrumentation of the tutors' roles. In other words, there isn't a consensus about the tasks of each role and how to represent each task. So, a modeling user task is required before any research about the instrumentation of the tutors' roles.

\subsection{Grouping of Users}

There are several researches that are interested in grouping different human actors. Learners are the primary beneficiaries of these works. Indeed, in the computer-supported collaborative learning (CSCL) area, there are several techniques for grouping learners into small groups. These methods have been applied for a long time in the schools of North America, for example. Jigsaw is the most commonly used method. It is based on grouping learners into small groups with a distribution of tasks assigned to each one of them (Tuparov et al., 2009). In fact, in Jigsaw method, each team is formed of four learners (or three in small groups). Participants will share their knowledge and collaborate for developing a common product.
The grouping of human users for various reasons has been studied by several researchers. Lappas and his co-authors (Lappas et al., 2009) proposed an algorithm to form teams of experts in social networks. To do any task, the authors proposed a technique for forming a team of experts having various skills that are required for this task. Furthermore, the proposed algorithm optimizes group size and communication cost between its members.

Forming groups of users in real-time to do unknown tasks has been studied by many researchers. Reviewing articles is a task that requires the formation of groups of reviewers to do a specific task (i.e. evaluate a scientific paper). Anagnostopoulos and his co-authors (Anagnostopoulos et al., 2012) proposed an algorithm to form groups of experts in social networks to decrease the costs of coordination among members. These authors proposed algorithms to be applied online or off-line.

As it was mentioned before, many researchers have studied different ways for grouping learners. Grouping process can be manual or automatic, and it can be carried out by teachers or tutors. Furthermore, it can be performed by the system, which takes into account learners' preferences, their cognitive levels or their learning styles. Deibel (2005) proposed to form groups of learners for increasing interaction during class work based on learning styles.

Other techniques and technologies can be used, such as classification (Zakrzewska, 2008), multi-agent systems (De Marchi et al., 2009) or interaction traces. In fact, the grouping of learners may be done by using their traces via a synchronously/asynchronously communication tool. For example, Shi and her colleagues (Shi et al., 2009) have used forums to form learning groups based on their behavior.

Group size differs from one system to another, and it is a principal criterion for forming groups. Many researches were done on small groups. However, with the emergence of social networks in the last decade, there are many researches that focus on large groups (Legras \& Tessier, 2003).

About collaboration among teachers, it aims at designing the learning content (learning objects, 
courses, etc.) collaboratively. Indeed, collaborative process is carried out during the preparation of a course's content. In the computersupported collaborative work/learning field, some researchers have studied the effects of collaboration among teachers. Lafifi and Touil (2010) proposed a collaborative authoring system that supports the collaboration of teachers during collaborative editing of learning objects and exercises. In addition, Hernández-Leo and her co-authors (Hernández-Leo et al., 2006) have developed an authoring tool that can be used by teachers (i.e. Collage). Using social networks platforms teachers can collaborate in order to co-edit learning objects or design solutions. In this sense, Hernández-Leo and her colleagues (Hernández-Leo et al., 2011) proposed LdShake, which is a web tool for social sharing and co-edition of learning design solution.

To our knowledge, there is no work that has studied the collaboration among human tutors in e-learning environments. This is mainly due to difficulties in modeling tutor on one hand, and taking into account the tutors' activities and coordination process on the other hand. Collaboration among tutors can solve several problems, including those discussed in the previous sections. In fact, tutors can share their experiences with others who are not experienced, especially novice ones who always need training for this profession. Absence of tutors for technical or professional problems can be overcome through the collaboration among them. In addition, learners can get many answers to their queries. Finally, several methods and tutoring styles can be used by different tutors belonging to the same group, which is considered as an added value of such systems.

In the next section, we present our new technique, which is based on the use of complementary skills of the tutors belonging to the same group.

\section{Principles of K-complementarity Technique}

\subsection{K-complementarity Applications}

The problem of grouping users according to the complementarity feature can be applied in sev- eral areas. The first area may be human resources management. The primary goal is forming groups or teams with complementary roles to set up or manage projects where collaboration is required.

Another area of application of this method is agriculture or agronomy. In fact, we can take advantage of this feature (i.e. complementarity) to get new species or animals.

In the military field, we can use the complementary technique to form groups of soldiers with complementary skills to compose ideal groups (including soldiers with most skills).

In the educational field, we can use complementarity to form groups of learners, teachers, tutors, designers, developers, etc. In collaborative learning, learners with different cognitive levels and skills can be grouped to form homogeneous groups. Teachers, in turn, can be grouped together to benefit from the experiences of other group's members in courses and exercises preparation. In fact, K-complementarity technique can be used in the case of the co-edition of courses and/or assessment exercises by a community of teachers having different competencies and skills. The tutors can collaborate to carry out their tasks of monitoring and supervising learners. This collaboration is taken into account by CSCTT (Computer Supported Collaborative TuToring) systems (Lafifi et al., 2012).

Finally, K-complementarity technique can also be used in an emergent field in technologyenhanced learning, which is the MOOC (Massive Open Online Courses). Indeed, MOOCs are considered as one of the main educational trends in the last years (Daniel, 2012; Hyman, 2012). As it is mentioned by Boyatt and his colleagues (Boyatt et al., 2014), the MOOC allows free participation to large numbers of learners from any geographical location. Furthermore, MOOCs are deployed in platforms that offer a set of services for supporting and managing the massive amount of learners (Alario-Hoyos et al., 2013). These learners require help and assistance during their pedagogical tasks in the MOOCs. In this case, tutoring task can be done by organizing tutors in groups having complementarity roles. The aim is to answer most of the learners' requests and decrease the efforts of tutors. 


\subsection{K-complementarity Technique Description}

The aim of this section is presentation of the general description of K-complementarity technique. It can be adapted to solve our problem, which is the formation of tutors' groups who have complementary roles and skills. So, the first step to take into account is identifying the tutors' roles to be adopted and used. The second step is proposing a tutor model to be used in the grouping process.

In our case, each tutor is represented by a vector having as size $\mathbf{t}$ (number of roles to use). The $\mathrm{K}$ groups that are obtained after the grouping task should have the majority of roles by merging the roles of tutors forming the same group.

We can express the K-complementarity problem as follows. We suppose that we have $\mathbf{n}$ users having each one $\mathbf{t}$ skills. Each user is modeled by a vector which has $\mathbf{t}$ elements. We want to get $\mathbf{K}$ groups, so that each group's skills are complementary. Each group is defined by a coefficient (between 0 and 1), which is called the complementarity coefficient.

We can formulate the problem as follows:

- Input: $\mathbf{n}$ vectors (representing the profiles of $\mathrm{n}$ users), $\mathbf{m}$ (size of groups).

- Output: K groups. Each one of them has the majority of roles, which are complementary.

For each group, we use a complementarity coefficient, which measures the degree of complementarity in each group. The closer this coefficient is to " 1 ", the more complementary the group is. When this coefficient is equal to " 1 ", the group is called "full complementary group".

We suppose that we have $\mathbf{n}$ vectors having $\mathbf{t}$ elements. The value of each element can be " 1 " or " 0 ". The rule used to calculate $\mathbf{K}$ is the following:

If $n \bmod m>=1$ then $K:=n$ div $m+1$ else $K:=n$ div $m$ (with $m>=1$ );
The coefficient of complementarity is calculated as follows:

$$
\begin{aligned}
& \operatorname{Coef}(\mathrm{i}) \\
& =\frac{\sum_{\mathrm{j}=1}^{\mathrm{t}}\left(\left(1-\frac{\left(\sum_{\mathrm{p}=1}^{\mathrm{m}} \mathrm{T}_{\mathrm{pj}}^{\mathrm{i}}\right)-1}{\mathrm{~m}}\right) * \max _{\mathrm{p}=\overline{1 \ldots \mathrm{m}}}\left(\mathrm{T}_{\mathrm{pj}}^{\mathrm{i}}\right)\right)}{\mathrm{t}}
\end{aligned}
$$

with:

Coef(i) is the complementarity coefficient of group $i$.

$\mathrm{T}_{\mathrm{pj}}^{\mathrm{i}}$ is the value of the element $\mathbf{j}$ of the vector $\mathbf{p}$ of group $\mathbf{i}$.

$\max _{\mathrm{p}=\overline{1 \ldots \mathrm{m}}}\left(\mathrm{T}_{\mathrm{pj}}^{\mathrm{i}}\right)$ is the maximum (0 or 1$)$ of the elements having position $\mathbf{j}$ of all the vectors of group i.

\section{Application of K-complementarity in a CSCTT System}

To test and validate the formulas of K-complementarity technique, we designed and implemented a computer supported collaborative tutoring system, called TutClass (Tutor Classifier). This system allows grouping tutors into small groups using K-complementarity method. It provides collaboration among tutors to satisfy all learners' needs; it improves tutors' skills, and it contributes to the training of new tutors in this job. Furthermore, it can be used by any educational institution adopting tutoring activity.

TutClass provides the users with some services like those of an e-learning system (learning objects downloading, assessment activities, etc.). Furthermore, it can be used by many students from different levels. In the actual version, only the students of the license regime can use the system.

The students found two main sub-systems: a learning management system and a tutoring system. They can download the learning objects according to their knowledge level, carry out some learning activities, resolve some exercises prepared by teachers and request the assistance of their tutors.

The main goals of TutClass are: encourage collaboration among tutors, provide learners with tutors having a good number of roles, provide 
tutors with much information about their learners, provide tutors with a private space requesting the assistance of their colleagues of the same group and facilitate the collaborative work, following up all traces of tutors and learners and grouping tutors using different methods.

\subsection{Modeling Tutors}

The K-complementarity technique can be adapted to solve the problem of composing $\mathrm{K}$ groups of tutors. Each tutor is defined by his model that has cognitive and tutoring profiles. The tutoring profile includes all the roles assigned to tutor.

For modeling our tutor, we decided to identify his roles. In the literature, we found many roles of the tutors without any classification. After six months of research, we decided to take fourteen roles. The lecturer can read (Lafifi et al., 2010) for more details about these roles and the main confusion made by many researchers about the tutors' roles. The main observation that we can quote is that each author or researcher has his point of view about the functions and the roles of the tutors. Furthermore, many authors used the same name, but with different functions. As a result, we made a taxonomy which can help the researchers to better understand the roles of tutors (see (Lafifi et al., 2010)). This taxonomy is used by a system called LETline (http://www.labstic.com/letline/).

In LETline system (Lafifi et al., 2010), fourteen roles were used. Initially, we thought that offering a lot of roles helps the tutor in his task of monitoring learners, but we noticed that many tutors had problems, especially the novice ones. In fact, after testing this system by real students, we found some difficulties. First, the students don't understand many roles of their tutors. Furthermore, the novice tutors don't understand some functions of some roles. The number of roles was judged as high by both students and tutors. Some students and tutors show that there are some overlapping functions of the tutors' roles. Finally, the interviewed tutors felt that there were redundant tasks in these roles. In addition, they expressed difficulties to understand and identify the tasks of each role.

So, we decided to eliminate some of these limits. To do this, we have worked with experts in cognitive psychology to reduce this number and keep only the essential roles and tasks. As a result, we kept nine roles (Pedagogue, Administrator, Coach, Evaluator, Supervisor, Facilitator, Organizer, Moderator and Psychologist). All the functions that can be carried out by the tutors belong to one of these roles.

Our goal is to form groups of four tutors in each one (the ideal size for a group according to several researchers in computer supported collaborative learning-CSCL-). Each tutor is represented by a Boolean vector (indicating role assignment or not) of size nine (number of adopted roles). We remember that grouping process is done by the complementary roles to make sure that each obtained group has the most of the roles.

In TutClass, tutoring profile of a tutor is represented by a vector of size nine. Each element of the proposed vector can take the value " 1 " for a role assigned to the tutor and " 0 " otherwise. To fill this vector, we used a questionnaire designed for this purpose (see Appendix 2 ). This questionnaire has a set of questions whose answers are used to determine the roles of the tutor. This questionnaire is established in collaboration with a team of experts from Guelma University. Other techniques can be used, such as data mining techniques or selfassignment process. In fact, there is a $\mathrm{PhD}$ research work in the LabSTIC laboratory that uses another method for initializing the tutor model without the questionnaire (Bendjebar \& Lafifi, 2013).

To initialize the tutoring profile of the tutors, they must complete a questionnaire about the existing roles. The assignment of roles is made according to the following procedure:

- Each role is defined by a set of questions.

- The tutor has the choice to answer by "yes", "no" or "maybe".

- Calculate the percentage of answers of the questions that are related to each role.

- A role is assigned to the tutor if the percentage of his answers is greater than a pail (for example 50\%).

For better explaining the tutoring profile structure, we give the following example. The tutor who has this profile is a pedagogue, a coach, a facilitator and an organizer. It will be better for him to work in the same group with the tutors who have other roles, such as administrator, evaluator or supervisor. 


\begin{tabular}{|c||c|}
\hline Pedagogue & 1 \\
\hline Administrator & 0 \\
\hline Coach & 1 \\
\hline Evaluator & 0 \\
\hline Supervisor & 0 \\
\hline Facilitator & 1 \\
\hline Organizer & 1 \\
\hline Moderator & 0 \\
\hline Psychologist & 0 \\
\hline
\end{tabular}

\subsection{K-complementarity Based Algorithm for Grouping Tutors}

The algorithm used for grouping tutors, which is called incremental complementarity algorithm, allows to create groups by incremental process. The steps taken by this algorithm are:

- Step 1: After initializing tutors' profiles, the algorithm takes a tutor $\mathbf{i}$ at random (represented by a vector $\left.T_{i}\right)$. Then, it puts the tutor i in the group $\mathrm{G}_{1}$ (initially $l:=1$ ).

- Step 2: Search for a vector $\mathrm{T}_{\mathrm{j}}$ (representing a tutor $\mathrm{j}$ ) that has a complementary profile to the profile of $T_{i}$. Add the tutor $j$ in the same group of the tutor $\mathrm{i}\left(\mathrm{G}_{\mathrm{l}}\right)$.

- Step 3: Calculate the union profile, which is obtained by using "or" operator: $\mathrm{T}_{\mathrm{i}}:=\mathrm{T}_{\mathrm{i}}$ "or" $\mathrm{T}_{\mathrm{j}}$.

- Step 4: Repeat from Step 2 until $\mathbf{m}$ tutors (four in the case of TutClass) in the group $\mathrm{G}_{1}$.

- While there are unassigned tutors, increment the number of groups (i.e. $l:=l+1$ ) and repeat from Step 1.

- If the last group has a single tutor, then he belongs to the first group.

In other words, the algorithm fetches vectors (i.e. tutors) that are complementary. It takes the first vector. Then, it searches for its complementary vector (or the closest one) from the other vectors in order to add it to the same group, and so on, until obtaining $\mathbf{m}$ vectors (i.e. tutors).

We remind the readers that our goal is to get homogeneous groups whose members have complementary roles. In other words, it minimizes the distance between groups and maximizes it within the group.

The pseudo code of this algorithm is represented by Algorithm 1 below.

This algorithm uses a function that has as input a vector and as output its complementary (i.e.

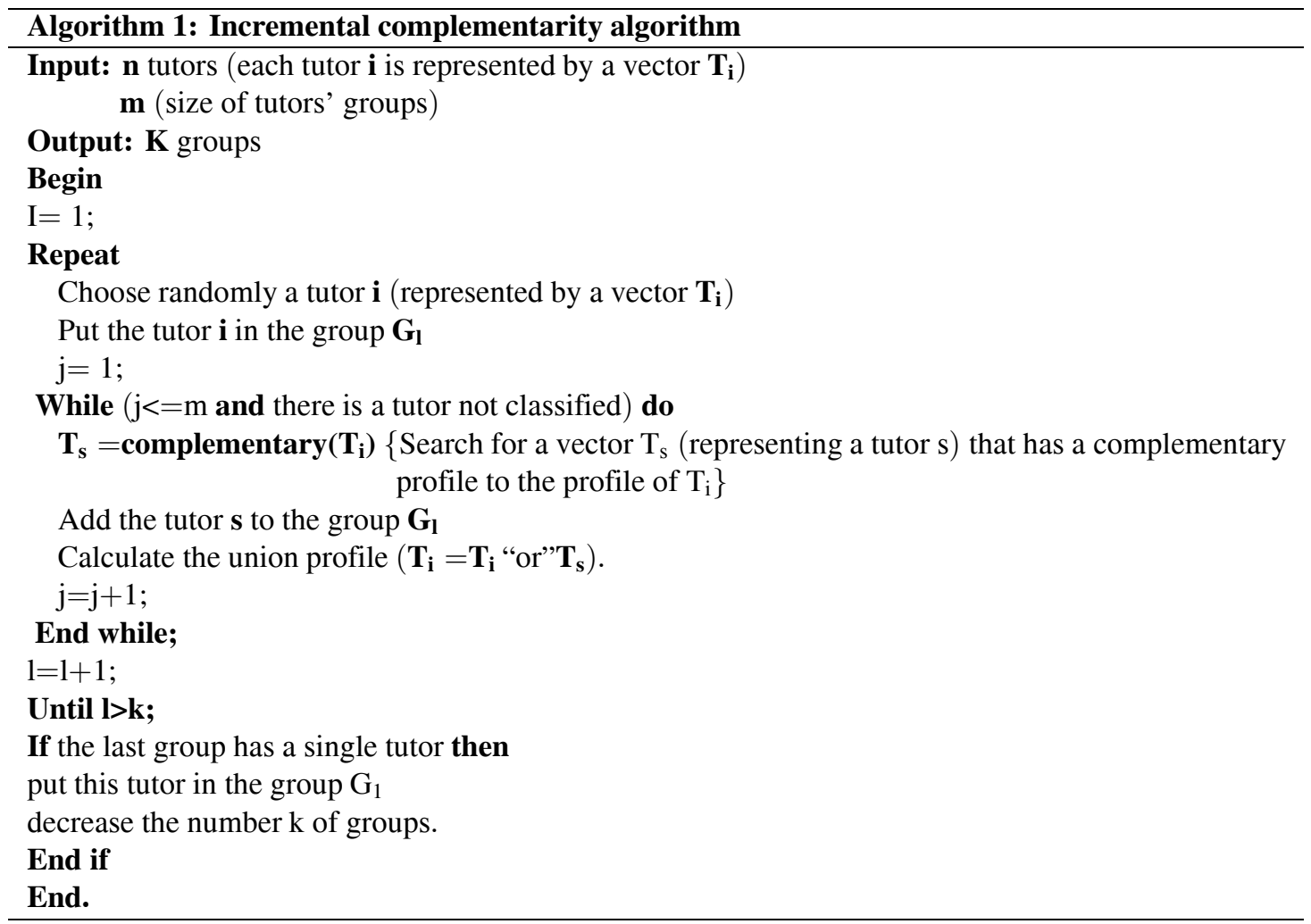


$\mathbf{T}_{\mathbf{s}}=$ complementary $\left.\left(\mathbf{T}_{\mathbf{i}}\right)\right)$. The pseudo-code of this function is given in Appendix 1.

\section{Experimentation}

To validate our proposals, we conducted an experiment at Guelma University (Algeria). This experiment had several goals:

1. Study the feasibility of K-complementarity technique and its adoption in CSCTT systems.

2. Study the usefulness of our vision on modeling tutors and the structure of the proposed model.

3. Extract the benefits and the limitations of our proposals to improve them.

Other objectives are planned, but they will not be taken into account in this paper. They will be the aim of further work.

1. Studying the effects of collaboration among tutors on tutor's performance, and

2. Studying the impacts of this collaboration on learners' cognitive levels.

\subsection{Participants}

In this experiment, twenty tutors were enrolled online in TutClass. These tutors are teachers and doctoral students. They follow up students from the license regime at Computer Science department ("Information systems" specialty). We keep in mind that tutoring is an accessory task according to the Algerian law (see http://www . joradp.dz/J02000/2009/001/ F_Pag.htm, pages 22-23). It can be ensured by teachers or students who have at least the academic Master degree.

\subsection{Methodology}

Students and tutors could use the system from any computer connected to the Intranet of the university. First of all, the features of our system were presented to all the users. Then, they used the system all the days. At the end of the experiment, two questionnaires were distributed to tutors and learners. The questions were about the system's features and users' appreciation.
In order to validate our approach and especially the K-complementary technique, we proposed to compare it with another algorithm. In fact, our system provides the administrator with other traditional grouping techniques. As it is mentioned in a previous section, providing other grouping techniques is one of the main objectives of TutClass.

The second offered algorithm is based on ordering tutors by using roles' number of each tutor. In other words, this algorithm will classify tutors according to the number of their roles (descending or ascending). Then, it puts in the same group the tutor having the greatest number of roles with those having the lowest number of roles, and so on.

This process is performed in two iterations:

- Iteration 1: The algorithm puts the first and the last tutor in the same group, and the second and the penultimate in the same group...until the end of the list of tutors.

- Iteration 2: Again, the obtained groups will be ordered. Then, the algorithm applies iteration 1 to get four tutors in the same group. If there is a group with a single tutor, it puts him in the first group.

\subsection{Results and Discussion}

After using TutClass system, we distributed two questionnaires to the tutors and the learners. The questions in the questionnaires were about the system's features and the encountered problems and difficulties. After the analysis of the answers of the learners and the tutors, and the results obtained from the system, we can confirm that our objectives are achieved and the results are very encouraging.

\subsubsection{Study the feasibility of K-complemen- tarity technique and its adoption in a CSCTT system}

Immediately after their enrollment, tutors were requested to answer a questionnaire to initialize their profiles. After applying the algorithm, we obtained the results that are listed in Figure 1 with the following parameters: $n=20$ (number of tutors), $m=4$ (number of tutors in each group), $t=9$ (representing tutors' roles) and $k=5$ (number of groups). For facilitating reading of the results, we mentioned the list 
of tutors and the complementarity coefficient of each group.

According to the previous screenshot (Figure 1), we notice that the coefficient of complementarity is between 0.69 and 0.88 with an average of 0.78 . Furthermore, the figure shows the time taken to do this grouping.

From the results mentioned above, we see that the group's members are heterogeneous and the groups are homogeneous (each group has eight to nine roles by combining the roles of its members). Therefore, we can say that our target goal is achieved.

For the second algorithm, we obtained the results that are outlined in Figure 2. From this figure, we see that the complementarity coefficient interval is $[0.52,0.83]$ with an average of 0.67 .

Furthermore, all the obtained groups after applying the proposed algorithm contain nine roles (i.e. all the roles). Concerning the obtained groups after applying the traditional algorithm, there is only one group that contains nine roles. Indeed, there are three groups that contain eight roles and one group having seven roles.

From these results, we can deduce that the Kcomplementarity based algorithm gives results better than the traditional one. The obtained groups contain between eight to nine roles, which is an excellent result. Finally, we mention that $90 \%$ of tutors have less than five roles.

\subsubsection{Study the usefulness of our vision on modeling tutors and the structure of the proposed model}

After the experimentation of our system, we noticed that the majority of tutors expressed their satisfaction about the model's components. However, some tutors found that the questions asked to initiate their profiles are too many. They want to get help for this task. In addition, some tutors wish to find mechanisms to simplify the initialization of their profiles (such as manual assignment or assignment by default). We remind the readers that our proposed tutor model is primarily based on his tutoring profile.

Finally, we can say that our model includes a lot of information that characterize tutors. However, the task of initializing the profiles can be improved. Doctoral work is underway to find other mechanisms and techniques to manage the tutor model.

\subsubsection{Extract the benefits and limitations of our proposals to improve them}

In the first experiment, we observed that tutors and learners were very pleased with this system and its features. In addition to monitoring function and learners' traces visualization,

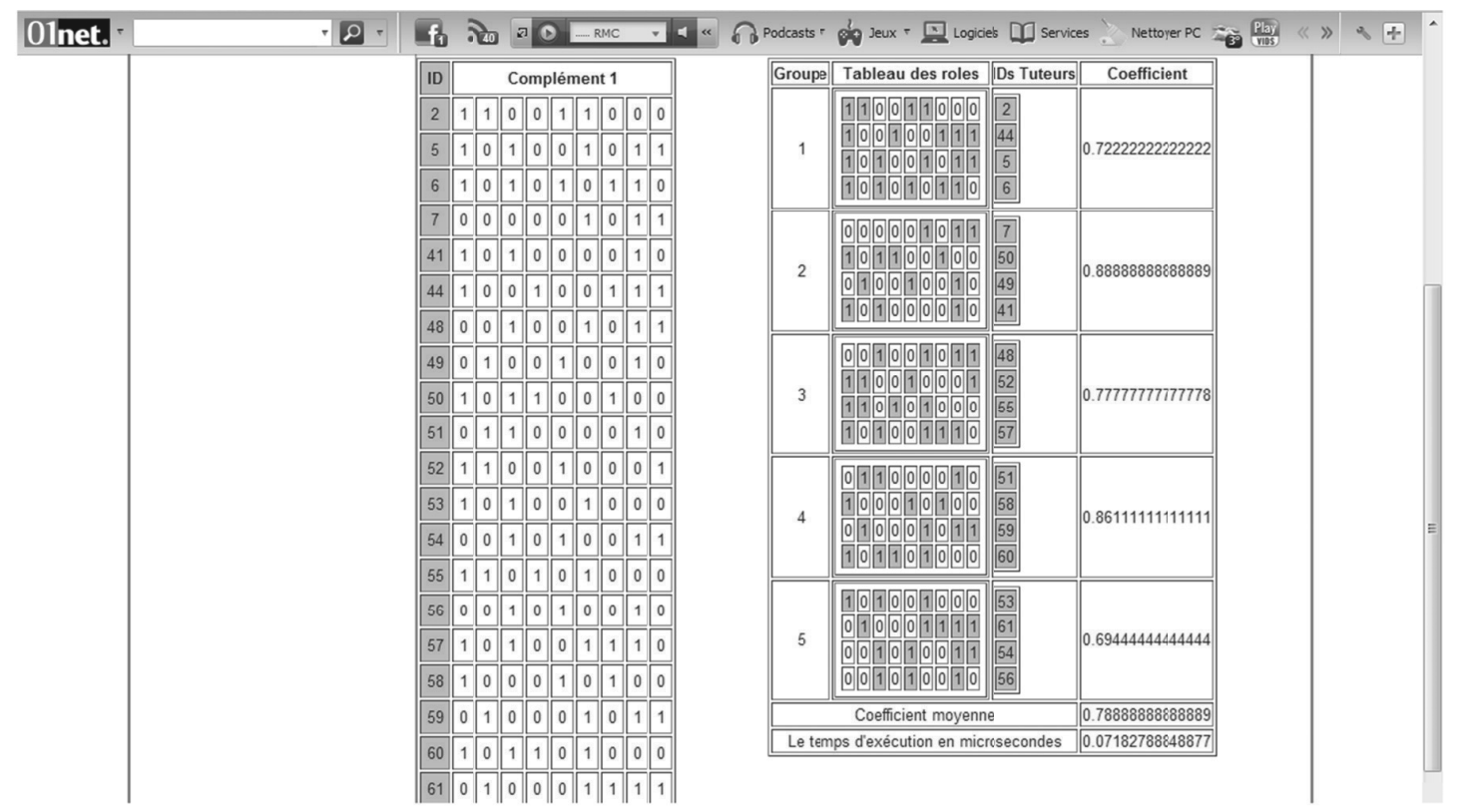

Figure 1. Groups of tutors obtained by applying K-complementarity technique. 


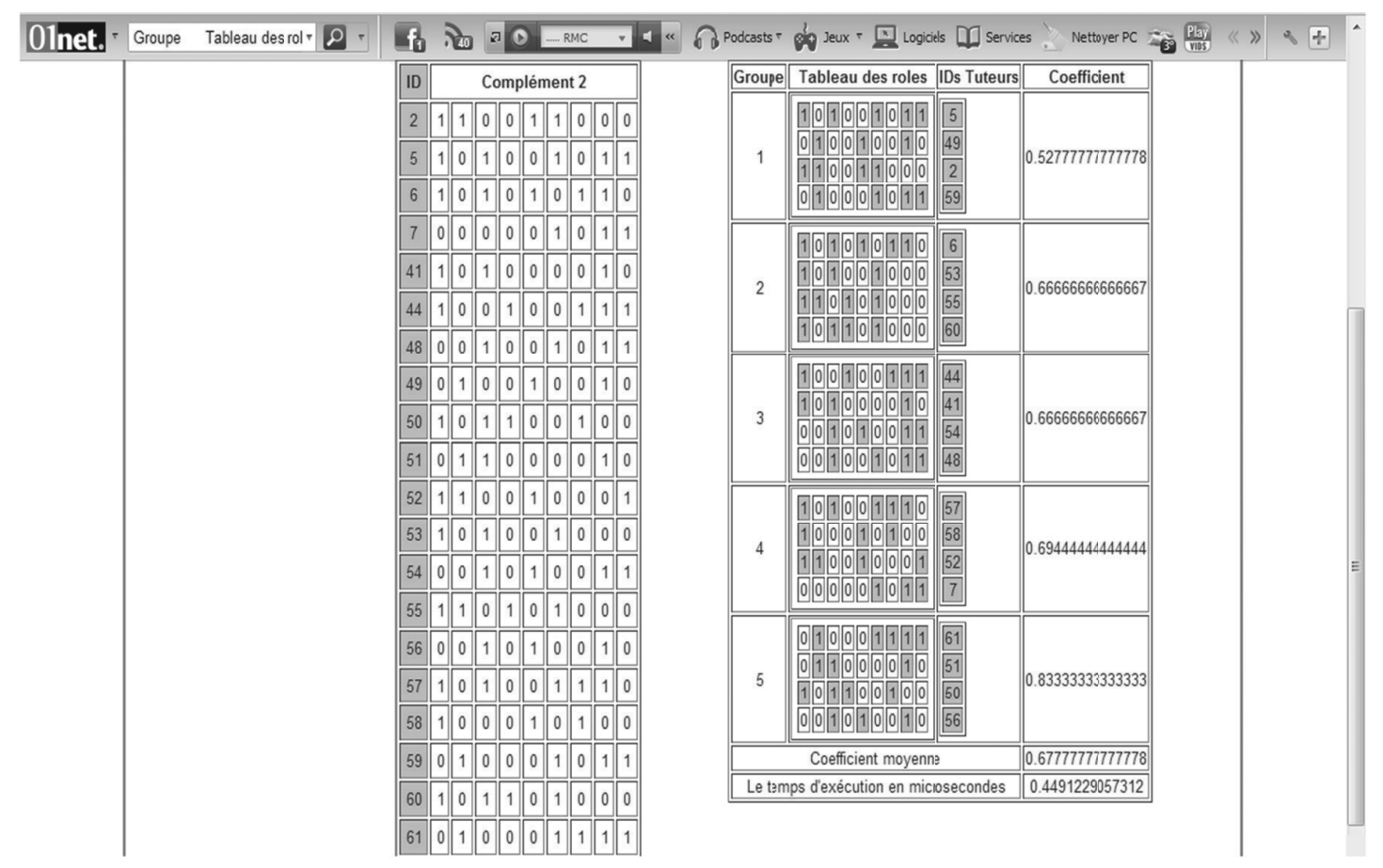

Figure 2. Grouping tutors using a traditional algorithm.

collaboration activity has been admired by the majority of tutors, especially those who practice the tutoring activity for the first time.

The questionnaire submitted to tutors contains 26 questions. These questions are about the features of the system, the roles and functions of tutors, and the quality of the collaboration among them. For example, to the question: How do you see the effectiveness of the use of the system? $70 \%$ of the tutors replied that the system is efficient, $20 \%$ that the system is very efficient and only $10 \%$ of them replied that the system is not efficient.

The majority of tutors are happy with their teammates. In fact, $80 \%$ of the tutors answer the question "Is the composition of the group good for you?" with "yes".

However, tutors met some difficulties and problems:

1. The majority of tutors wanted to have a filtering tool of learners' traces. They noticed that there were many useless learners' traces.

2. The collaboration space has a lot of useless information.

3. Some tutors express the problem of the absence of tutors grouping method according to their affinity.
4. The collaboration tracking tool requires improvement. Some tutors have found many difficulties during its use.

On the side of learners, they appreciated the features of the system. However, they expressed some difficulties:

1. Students cited the absence of the ability to save the displayed traces and therefore, its reuse.

2. A research feature of specific learners' traces is absent from the system.

3. Students mentioned the lack of tools for saving conversations made by their tutors.

\section{Conclusion and Future Work}

Tutoring activity has become an essential task in distance learning environments. Several researchers have focused their researches on an emerging track, which is the instrumentation of tutors' roles (Garrot, 2008; Rasoavelorina, 2012). In these researches, several appointments were given to the term of "tutor" without a consensus or standardization of his roles and functions. In this paper, we presented our contribution and vision about the instrumentation of online tutors' roles. 
Our contributions focus on the proposal of a new approach to tutor modeling and a new tutors grouping technique. In fact, we contribute to the efforts made in the instrumentation of tutors' roles by proposing a new tutor model structure, which is based on his cognitive and tutoring profiles. The tutoring profile includes roles that we found essential for taking into account all the assistance requests submitted by learners.

Our second contribution concerns the proposal of a new tutors grouping method. Indeed, if a lot of research was doing on learners grouping for various reasons (collaboration, performance prediction, etc.); no work has been done on the grouping of tutors in e-learning systems. This led us to study the impact of grouping tutors into groups and propose new methods. As a result, we proposed a new technique called $\mathrm{K}$ complementarity, which is based on the tutoring profile of tutors. The obtained groups are characterized by a complementarity coefficient, which measures the degree of complementarity between the members of each group.

To validate our ideas and proposed formulas, our contributions have been implemented by a system, which facilitates the collaboration among tutors. The developed system (i.e. TutClass) was tested at an Algerian University where good results were obtained. From these results, several improvements can be considered. Indeed, several lines of research are considered in short and medium term.

Firstly, we want to study the effects of collaboration among tutors on the performance of learners on one hand and on the tutors themselves on the other. This collaboration has double objectives. On one side, it can help tutors to respond to the assistance requests that are sent by learners, by collaborating with other tutors when the target tutor doesn't know how to solve requests individually or when the response is considered unsatisfactory by the learner requesting assistance. On the other side, this collaboration offers an adaptive space for the exchange of experiences between the tutors. So, collaboration activity can promote tutors' training and increase their levels.

Secondly, another research work that we want to start is the filtering of traces left by human actors during tutoring process. These traces must undergo several treatments before being filtered. Thirdly, another future work concerns the study of different techniques for initializing the profile of the tutor and the establishment of a standard that can be adopted by any e-learning platform adopting tutoring.

Finally, we aim to conduct another experiment of the developed system before its final use at any higher-education institution. This experiment, on a larger sample, can validate our choices and in particular, the proposed technique for grouping tutors and the usefulness of the complementarity coefficient.

\section{References}

[1] M. AARNio, S. LindBlom-YläNNE, J. NiEMINEN, E. PYÖRÄLA, How do tutors intervene when conflicts on knowledge arise in tutorial group? $A d$ vances in Health Sciences Education, (2013), 1-17.

[2] C. Alario-Hoyos, M. PÉrez-Sanagustín, C. Delgado-KloOS, G. H. A. PARADA, M. MuÑoz-Organero, A. RodrigueZ-DE-LASHERAS, Analysing the impact of built-in and external Social Tools in a MOOC on Educational Technologies. Presented in the Proceedings of the 8th European Conference on Technology Enhanced Learning, EC-TEL 2013, (2013) Paphos, Cyprus.

[3] A. Anagnostopoulos, L. Becchetti, C. CAstillo, A. GiOnIS, S. LeONARDi, Online Team Formation in Social Networks. Presented in the Proceedings of the 21st International World Wide Web Conference (WWW 2012), (2012) Lyon, France.

[4] P. BARKER, On Being an Online Tutor. Innovations in Education and Teaching International, 39(1) (2002), 3-13.

[5] S. Bendjebar, Y. LAFIFI, Initializing the Tutor Model Using K-Means Algorithm. Modeling Approaches and Algorithms for Advanced Computer Applications. In Studies in Computational Intelligence (A. AMINE, O. AIT MOHAMED, L. BEllATRECHE, Eds.), (2013) pp. 389-398.

[6] P. A. BERNATCHEZ, Vers une nouvelle typologie des activités d'encadrement et du rôle des tuteurs. Distances, 6(1) (2003), 5-25.

[7] R. Boyatt, M. Joy, C. Rocks, J. Sinclair, What (use) is a MOOC? Presented in the Proceedings of the 2nd International Workshop on Learning Technology for Education in Cloud (LTEC 2013), (2013) Kaohsiung, Taiwan.

[8] V. Cohen-Scali, Sexe du tuteur et perception de l'avenir professionnel de jeunes en alternance: une recherche qualitative. Pratiques psychologiques, 19 (2013), 265-281.

[9] A. DAEle, F. DocQ, Le tuteur en ligne, quelles conditions d'efficacité dans un dispositif d'apprentissage collaboratif à distance? Presented at the Proceedings of 19ème colloque de l'AIPU, (Association Internationale de Pédagogie Universitaire), (2002) Louvain-la-Neuve. 
[10] J. DANIEL, Making Sense of MOOCs: Musings in a Maze of Myth, Paradox and Possibility. Technical report, Korea National Open University, 2012.

[11] A. C. B. De Marchi, M. C. Moraes, C. D. Testa, CV-Muzar Using a Multiagent System for Group Formation. Education and Technology for a Better World, 302 (2009), 159-168.

[12] S. DeCAMPS, C. DEPOVER, La perception du tutorat par les acteurs de la formation à distance. In $L e$ tutorat en formation à distance $(\mathrm{C}$. DEPOVER ET AL. Eds.), (2011) pp. 109-124. De Boeck.

[13] K. DEIBEL, Team formation methods for increasing interaction during in-class group work. Presented in the Proceedings of the 10th Annual SIGCSE Conference on Innovation and Technology in Computer Science Education, (2005) New York, NY.

[14] M. De SMet, H. V. KeER, B. D. Wever, M. VAlcke, Cross-age peer tutors in asynchronous discussion groups: Exploring the impact of three types of tutor training on patterns in tutor support and on tutor characteristics. Computers \& Education, 54(4) (2010), 1167-1181.

[15] P. Dillenbourg, Pour une conception intégrée du tutorat de groupe. In Le tutorat en formation à distance (C. DEPOVER ET AL. Eds.), (2011) pp. 171-194. De Boeck.

[16] C. Depover, J. J. Quintin, Le tutorat et sa mise en œuvre. In Le tutorat en formation à distance (C. Depover ET AL. Eds.), (2011) pp. 39-60. De Boeck.

[17] D. H. J. M. Dolmans, I. H. A. P. Wolfhagen, R. J. I. HoOgenboOM, C. P. M. VAN DeR Vleuten, Is Tutor Performance Dependent on the Tutorial Group's Productivity?: Toward Further Resolving of Inconsistencies in Tutor Performance. Teaching and Learning in Medicine: An International Journal, 11(4) (1999), 186-191.

[18] E. GARROT, Plate-forme support à l'interconnexion de communautés de pratique (icp). Application au tutorat avec te-cap. PhD. Thesis, INSA Lyon, France, 2008.

[19] V. Glikman, Formation à distance: au nom de l'usager. Distances, 3(2) (1999), 101-117.

[20] V. GLiKman, Apprenants et tuteurs : une approche européenne des médiations humaines. Education permanente, 152 (2002), 55-69.

[21] V. GLIKMAN, Le tutorat en formation à distance. Tuteur à distance: une fonction, un métier, une identité? (C. DEPOVER ET AL. Eds.), (2011) pp. 280. De Boeck.

[22] S. Hayashi, K. Tsunekawa, C. Inoue, Y. FukUZAWA, Comparison of tutored group with tutorless group in problem-based mixed learning sessions: a randomized cross-matched study. BMC Medical Education, 13(158) (2013). http: //www. biomedcentral . com/14726920/13/158
[23] D. HernándeZ-LeO, E. D. VILlasclaras-FERNANDEZ, J. I. ASENSIO-PEREZ, Y. DIMITRIADIS, I. M. JORRIN-ABELlAN, I. RUIZ-REQUIES, B. RUBIAAVI, COLLAGE: A Collaborative Learning Design Editor Based on Patterns. Educational Technology \& Society, 9(1) (2006), 58-71.

[24] D. Hernández-Leo, R. Lauren, M. A. Arralero, J. CHACón, M. CARrió, P. MORENO, J. Blat, LdShake: Learning design solutions sharing and coedition. Computers \& Education, 57(4) (2011), 2249-2260.

[25] P. HyMAN, In the Year of Disruptive Education. Communications of the ACM, 55(12) (2012), 20-22.

[26] A. Jelfs, J. T. E. Richardson, L. Price, Student and tutor perceptions of effective tutoring in distance education. Distance Education, 30(3) (2009), 419-441.

[27] J. L. KERRIDGE, Supporting student nurses on placement in nursing homes: The challenges for the link-tutor role. Nurse Education in Practice, 8(6) (2008), 389-396.

[28] B. Kopp, M. C. Matteucci, C. Tomasetto, Etutorial support for collaborative online learning: An explorative study on experienced and inexperienced e-tutors. Computers \& Education, 58(1) (2012), 12-20.

[29] Y. Lafifi, K. Azzouz, H. Faci, W. Herkas, Dynamic Management of Tutor's Roles in an Online Learning System. International Journal of Learning Technology (IJLT), InderScience Publication, 5(2) (2010), 103-129.

[30] Y. LAFIFI, G. TOUIL, Study of the Impact of Collaboration among Teachers in a Collaborative Authoring System. Journal of Information Technology Education: Innovations in Practice, 9 (2010).

[31] Y. LAFIFI, M. HADJERIS, A. SERIDI, R. BOURBIA, Architecture of a collaborative tutoring system. Procedia - Social and Behavioral Sciences, 31 (2012), 459-463.

[32] T. LApPAS, K. LIU, E. TerzI, Finding a Team of Experts in Social Networks. Presented in the Proceedings of the Fifteenth ACM SIGKDD Conference on Knowledge Discovery and Data Mining, (2009) Paris, France.

[33] F. LEGRAS, C. TESSIER, LOTTO: group formation by overhearing in large teams. Presented in the Proceedings of the 2nd International Joint Conference on Autonomous Agents and Multi-Agent Systems, (2003) Melbourne, Australia.

[34] H. Li, C. Sun, L. Zhou, G. Zhang, W. Su, Study on Tutor Team of Full-time Professional Degree Graduates. Presented in the Proceedings of the 2 nd International Conference on Green Communications and Networks, (2012) Gandia, Spain.

[35] F. MAngenot, Spécificité du tutorat en langues. In Le tutorat en formation à distance (C. DEPOVER ET AL. Eds.), (2011) pp. 213-225. De Boeck. 
[36] J. T. Nisbet, M. D. Haw, A. J. Fletcher, The role of tutors in peer led teaching. Education for chemical engineers, 9(1) (2014), 15-19.

[37] D. Owen, B. Hudson, T. TERVOLA, Open and flexible learning? An evaluation of student and tutor experiences in a European e-learning community. Technology, Pedagogy and Education, 15(3) (2006), 291-306.

[38] D. PERAYA, Le tutorat en formation à distance: le cadre applicatif. In Le tutorat en formation à distance (C. DEPOVER ET AL. Eds.) (2011) pp. 125-136. De Boeck.

[39] K. PoraysKa-Pomsta, C. Mellish, Modelling human tutors' feedback to inform natural language interfaces for learning. International Journal HumanComputer Studies, 71(6) (2013), 703-724.

[40] A. L. Rasoavelorina, Rendre compte des effets des interventions des tuteurs à travers une Approche Orientée Indicateurs. PhD. Thesis, University of Maine, France, 2012.

[41] S. RHODES, A. JINKS, Personal tutors' views of their role with pre-registration nursing students: An exploratory study. Nurse Education Today, 25(5) (2005), 390-397.

[42] J. RODET, Tuteur à distance, entre fonction et métier. In Inffo Flash, 719 (2008).

[43] G. SALMON, E-moderating: The key to teaching and learning online. Kogan Page, London, 2000.

[44] G. SALMON, E-moderating: The key to teaching and learning online (2nd ed). RoutledgeFalmer, London, 2003.

[45] F. Shah, M. Evens, J. Michael, A. Rovick, Classifying Student Initiatives and Tutor Responses in Human Keyboard-to-Keyboard Tutoring Sessions. Discourse Processes, 33(1) (2002), 23-52.

[46] C. Shaoming, Discourse analysis of e-tutor's role in online collaborative learning system. Presented in the Proceedings of the International Conference on E-business and E-government (ICEE), (2011) Shanghai, China.

[47] X. SHI, J. ZHU, R. CAI, L. ZHANG, User Grouping Behavior in Online Forums. Presented in the Proceedings of the Fifteenth ACM SIGKDD Conference on Knowledge Discovery and Data Mining, (2009) Paris, France.

[48] G. Tuparov, D. Tuparova, I. Zafirova, The "Jigsaw" collaborative method in e-learning environment Moodle. Presented in the Proceedings of the 2009 International Conference on Computer Systems and Technologies and Workshop for PhD Students in Computing, (2009) Ruse, Bulgaria.

[49] K. Waite, P. Gannon-Leary, J. CARr, The Role and Responsibilities of an E-tutor Librarian. Journal of Library \& Information Services in Distance Learning, 5(4) (2011), 129-148.
[50] S. C. Weigle, G. L. NELSON, Novice tutors and their ESL tutees: Three case studies of tutor roles and perceptions of tutorial success. Journal of Second Language Writing, 13(3) (2004), 203-225.

[51] M. Xenos, T. Papadopoulos, Computer Aided Evaluation of Higher Education Tutors' Performance. Studies in Educational Evaluation, 33(2) (2007), 175-196.

[52] D. ZAKRZEwSKA, Using Clustering Technique for Students' Grouping in Intelligent E-learning Systems. Adaptivity and Personalization in Ubiquitous Learning Systems, (2008) Springer Berlin Heidelberg, pp. 403-410.

Received: March, 2014 Revised: June, 2014 Accepted: July, 2014

Contact address:

Yacine Lafifi

LabSTIC Laboratory University 8 May 1945 Guelma BP 401

Guelma, 24000 Algeria

e-mail: Laf_yac@yahoo.fr

Safia Bendjebar LabSTIC Laboratory University 8 May 1945 Guelma BP 401

Guelma, 24000 Algeria

e-mail: bendjebar_s@hotmail.fr

Amina Zedadra

LabSTIC Laboratory University 8 May 1945 Guelma BP 401

Guelma, 24000 Algeria

e-mail: zedadra_a@yahoo.fr

YACINE LAFIFI is currently working as an Associate Professor at the Computer Science Department of Guelma University, Algeria. Also, he is a senior researcher at LabSTIC laboratory (Guelma University, Algeria). He works in e-learning research field since 1997. He received his Ph.D. in computer science from the University of Annaba (Algeria) in 2007. He has several published papers in conferences and journals. Furthermore, he is an editorial board member of many international journals. Currently, he works on educational data mining techniques, CSCL, recommender systems, MOOC and human tutoring systems.

SAFIA BENDJEBAR is currently a $\mathrm{PhD}$ student in computer science at LabSTIC Laboratory (Guelma University, Algeria). She has worked for three years on educational data mining techniques. She is preparing a $\mathrm{PhD}$ thesis about the modeling of tutors in e-learning systems. Her current research concerns e-learning systems, tutors modeling, classification, and data mining techniques.

AMINA ZEDADRA is currently a $\mathrm{PhD}$ student in computer science at the University of Guelma, Algeria. Also, she has been preparing her PhD thesis at the Laboratory of Research (LabSTIC) since 2012. Her PhD research is the use of learning traces to improve collaborative learning environments. Her current research interests include e-learning, bio-informatics and multi-agent systems. 


\section{Appendix 1}

The proposed algorithm uses a function for calculating the complementarity of a vector $T_{i}$. The code of this function is the following.

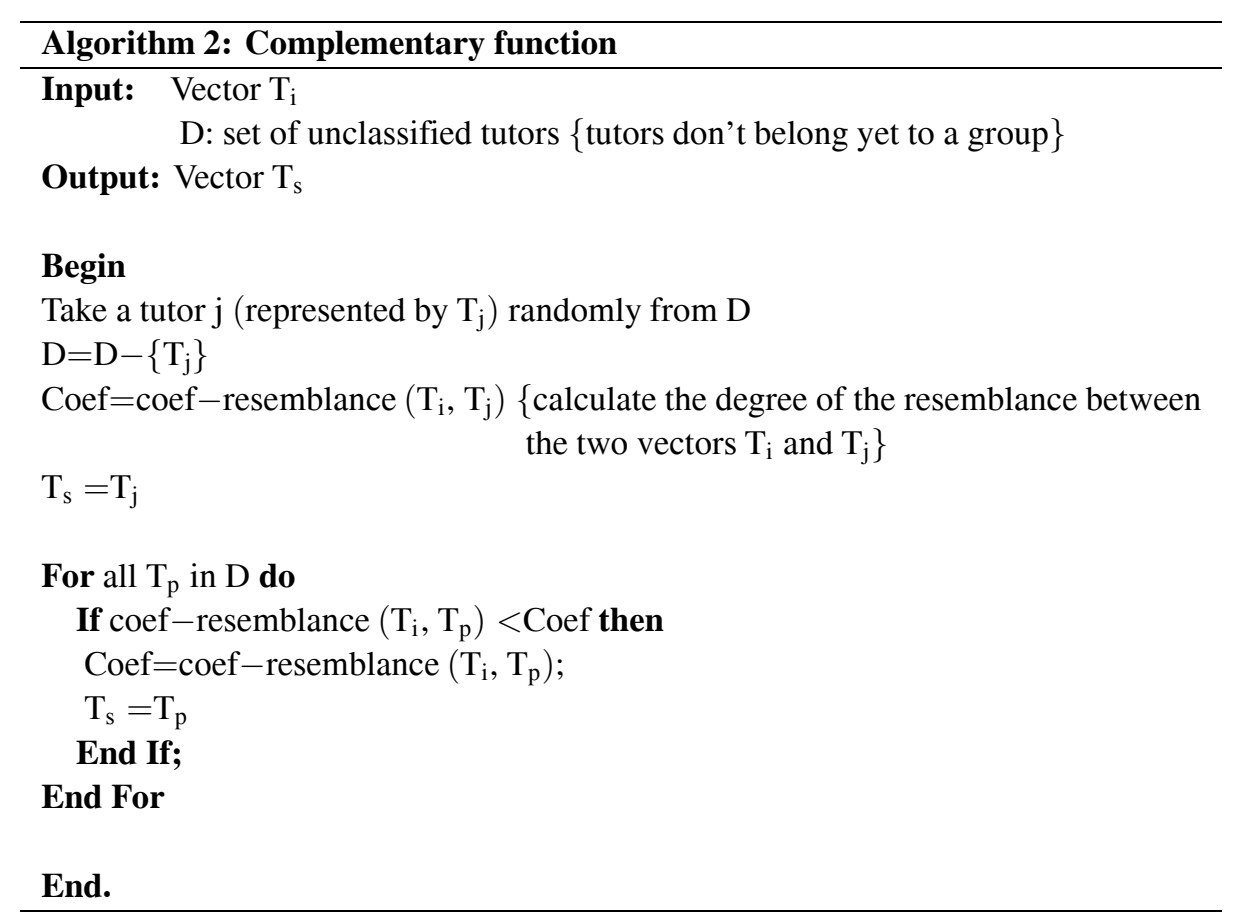

For calculating the degree of resemblance between two vectors $T_{i}$ and $T_{j}$ (i.e. coef-resemblance $\left(\mathbf{T}_{\mathbf{i}}\right.$, $\left.\mathbf{T}_{\mathbf{j}}\right)$ ), we use the following code:

$\mathrm{S}=0$

For $\mathrm{c}=1$ to $\operatorname{size}\left(\mathrm{T}_{\mathrm{i}}\right)$ do

If $\mathrm{T}_{\mathrm{i}}[\mathrm{c}]=\mathrm{T}_{\mathrm{j}}[\mathrm{c}]$ then

$\mathrm{S}=\mathrm{S}+1$

End If

End For

Coef-resemblance $\left(T_{i}, T_{j}\right)=S$ 


\section{Appendix 2}

The questionnaire used for initializing the tutoring profile of a tutor.

\begin{tabular}{|c|c|c|c|c|}
\hline \multirow{2}{*}{$\begin{array}{c}\text { Tutors' } \\
\text { roles }\end{array}$} & \multirow{2}{*}{ Can you perform the following tasks? } & \multicolumn{3}{|c|}{ Response } \\
\hline & & Yes & No & Maybe \\
\hline \multirow{6}{*}{\begin{tabular}{l}
$\stackrel{0}{0}$ \\
0 \\
0 \\
000 \\
\multirow{0}{0}{} \\
0 \\
0
\end{tabular}} & Identify the learning difficulties & & & \\
\hline & Establish the objectives of the learning objects & & & \\
\hline & Solicit the exchange of the resources between the learners & & & \\
\hline & Seek the establishment of relations between some parts of the course & & & \\
\hline & Provide resources related to the contents of the studied subjects & & & \\
\hline & $\begin{array}{l}\text { Select a set of pedagogical resources that you must schedule and } \\
\text { complete with your own production, in order to propose them to } \\
\text { the learners }\end{array}$ & & & \\
\hline \multirow{7}{*}{ 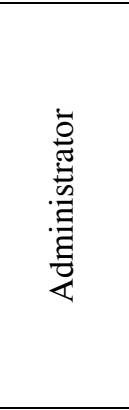 } & Answer the various administrative questions & & & \\
\hline & $\begin{array}{l}\text { Remind learners about the deadlines (calendar: dates of the enrollment, } \\
\text { examination dates, etc.) }\end{array}$ & & & \\
\hline & Answer general questions about the courses & & & \\
\hline & Check whether the objectives of the courses are known and understood & & & \\
\hline & Control the order and the flow of the discussions' subjects & & & \\
\hline & Monitor the members who are apart from the discussions & & & \\
\hline & Monitor closely the progress of the learners' activities & & & \\
\hline \multirow{6}{*}{ 仓̊ } & Correct the errors of the learners & & & \\
\hline & Establish a work plan & & & \\
\hline & $\begin{array}{l}\text { Guide the learners toward the best technological and pedagogical } \\
\text { choices }\end{array}$ & & & \\
\hline & $\begin{array}{l}\text { Guide the learners in their research query, therefore to develop skills in } \\
\text { the research field }\end{array}$ & & & \\
\hline & Give feedback on the interventions of the learners & & & \\
\hline & Facilitate the learning process for the learners & & & \\
\hline \multirow{5}{*}{ 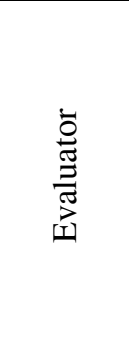 } & $\begin{array}{l}\text { Evaluate and certify the acquired knowledge and the skills developed } \\
\text { by the learners }\end{array}$ & & & \\
\hline & $\begin{array}{l}\text { Evaluate the needs, the difficulties, the rhythm and the preferences of } \\
\text { each learner }\end{array}$ & & & \\
\hline & Solicit the self-assessment of the learners' activities & & & \\
\hline & Create detailed learning objects during the progression of the course & & & \\
\hline & $\begin{array}{l}\text { Establish the objectives of the activities and work on the specification } \\
\text { of each learner's course }\end{array}$ & & & \\
\hline \multirow{4}{*}{ 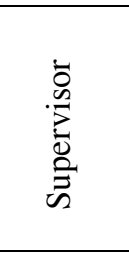 } & $\begin{array}{l}\text { Technical guide: answer simple questions about technical problems } \\
\text { (you must be familiar with the system) }\end{array}$ & & & \\
\hline & Help the learners to present, communicate, participate and interact & & & \\
\hline & Help the learner to choose his personal projects & & & \\
\hline & Help the learner to reflect on his own tasks & & & \\
\hline \multirow{4}{*}{ 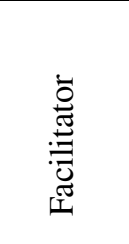 } & $\begin{array}{l}\text { Clarify and advise the learners on the adequate choice of communication } \\
\text { tools according to the type and the moments of the activity }\end{array}$ & & & \\
\hline & Provide indicators to facilitate the access to the information & & & \\
\hline & Clarify points of methodology & & & \\
\hline & Help the group to specify common projects & & & \\
\hline
\end{tabular}




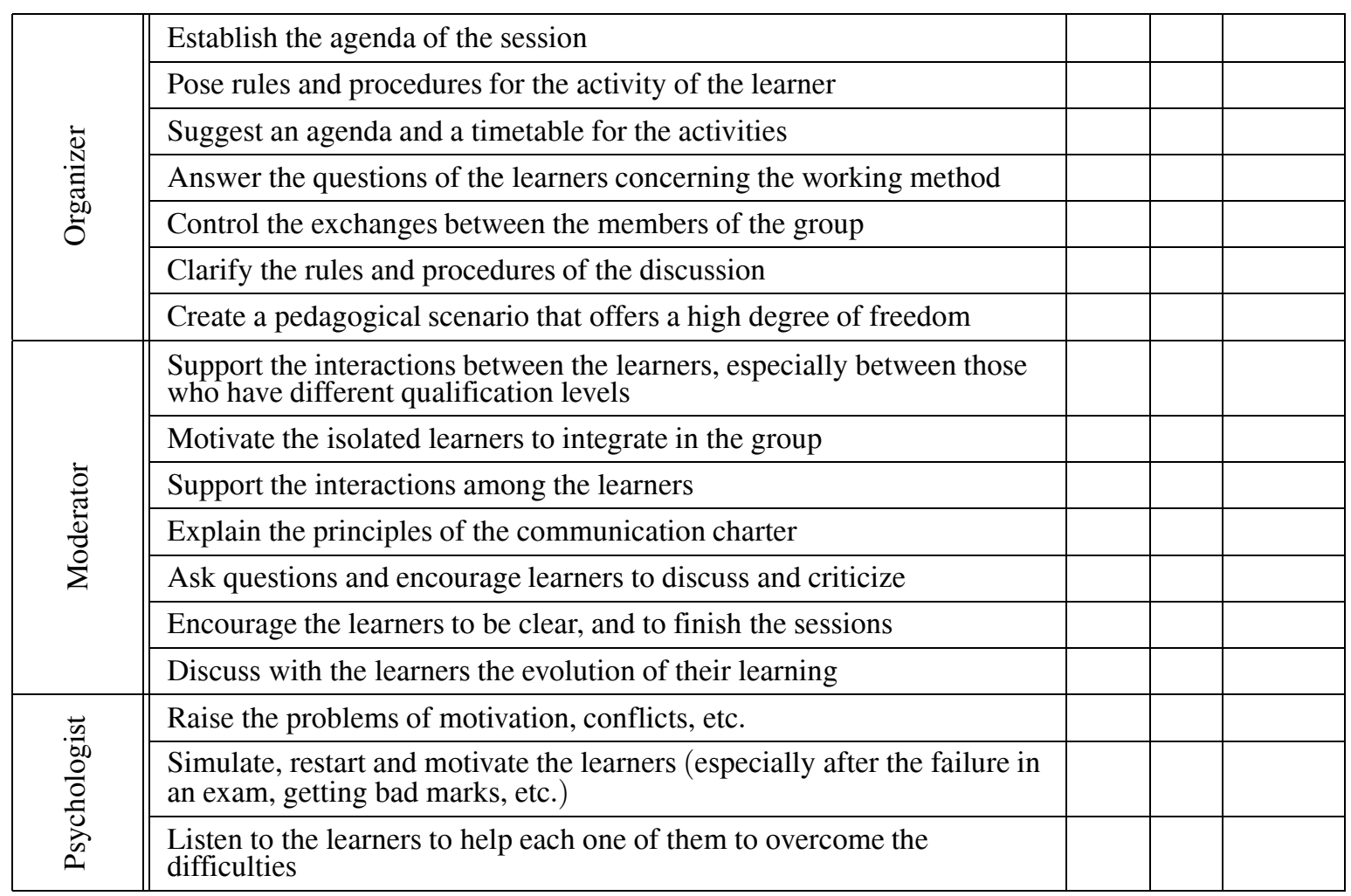

